\title{
INTR0DUCTION
}

\section{Intellectual disability and its effects on society}

$\mathrm{M}$ illions of people around the world live with an intellectual disability, where the estimated prevalence in higher-income countries is between 1 and 3\%. ${ }^{1-4}$ In Mexico alone, according to INDESOL (National Social Development Institute), some 2925000 people live with some type of intellectual disability. ${ }^{5}$ These conditions have an important social and economic impact, particularly because they can be accompanied by family-level psychological problems, discrimination, catastrophic costs that are not covered by the State due to the lack of universal access to health care and perhaps, most especially, lack of appropriate social services, principally educational programs focusing on social and vocational integration. In addition, people with intellectual disabilities have a greater risk of experiencing physical and mental health problems ${ }^{6-8}$ and are vulnerable to chronic disease at an earlier age, among other factors, due to a high prevalence of sedentary lifestyles. ${ }^{9-11}$

Early detection of intellectual disability is rare to nonexistent in middle-income countries such as Mexico. Important elements of this problem include the lack of use of valid and reproducible population-level tools for carrying out a precise diagnosis and prognosis and the lack of professionals trained to identify and manage intellectual disability properly. Intellectual disability is most successfully managed in a holistic, and therefore multidisciplinary, manner. In the study and treatment of this condition, diverse disciplines should be employed, including psychiatry, psychology, public health, pedagogy, genetics, ergonomics and social sciences such as sociology and anthropology, among others. Unfortunately, in most middle- and low-income countries such as Mexico there is a lack of health and education professionals with the skills and training to recognize the signs and symptoms of intellectual disability and make referrals. Even if referrals were feasible, institutions that promote social integration and an independent life project for people with intellectual disabilities are virtually nonexistent in Mexico.

Intellectual disability has generally been absent from the political, social and economic agenda of Latin American countries -Mexico being no exception to this trend. People with intellectual disabilities are not taken into account when developing policy and planning related to health services, while the predominant educational proposals are not based on current scientific evidence. In addition, only a very limited amount of research in the field of intellectual disability has been carried out in the region. ${ }^{12,13}$

We are thus pleased to present a special issue of the journal Salud Pública de México, entitled "Intellectual disability". This special issue sets a precedent for the Latin American region, where scientific publications in the field of intellectual disability are sorely lacking. As guest editors, we were extremely pleased that research groups from a variety of nations participated in this effort, including Australia, the United States, Belgium, France, Great Britain, Canada, India, Israel, Germany, the Netherlands and Mexico.

This special issue includes cutting-edge conceptual perspectives and research on the social and health needs of individuals with intellectual disability. The articles touch upon a broad range of aspects of intellectual disability, including etiopathogenesis, a description of the world atlas of intellectual disability promoted by the World Health Organization, as well as diverse social, ethical and rights-related issues germane to intellectually disabled persons. The authors included in this special issue identify basic elements of this field, including access to and quality of health and social services, 
sexual and reproductive rights and responsibilities, the need for policy and interventions to promote physical activity and healthy lifestyles in this population, and ways of organizing free time in order to guarantee mental health and wellbeing. A variety of interventions to promote social and employment integration, principally in developed countries, but also in Mexico, are also discussed. The Center for Integral Training and Development (CADI, per its abbreviation in Spanish), in Mexico has assembled a multidisciplinary group which has accumulated 25 years of experience. However, there is a stark contrast between countries such as Mexico and higher-income nations, in that the latter have generally included in the public agenda provision of services to support the social integration of people with intellectual disability. ${ }^{14}$

The body of international literature reporting research on intellectual disability has important gaps in knowledge, especially related to interventions, use of services, legislation and policy. This special issue attempts to contribute in some small manner, not only to developing the potential and promoting social inclusion of people with intellectual disability -a basic set of services that the State should provide-, but also as part of an organized social response to this population group's social, economic and health needs. The responsibility of such a social response should lie on public policy rather than philanthropic initiative. This issue highlights the need to develop research on intellectual disability which not only takes into account the existing enormous gaps in knowledge about this issue, especially in middle- and low-income countries and specifically in Latin America, ${ }^{15,16}$ but also proposes that research be used as an evidence base for the development of new health and social policies aimed at improving the quality of life of people with intellectual disability and their families. ${ }^{17,18}$ Taken together, research and evidence, policy and implementation of services, are needed to guarantee the right of people with intellectual disability to healthy, dignified and high quality lives.

Eduardo Lazcano-Ponce,
Guillermina Rangel-Eudave,
Gregorio Katz.

\section{References}

I. Petterson B, Bourke J, Leonard H, Jacoby P, Bower C. Co-occurrence of birth defects and intellectual disability. Paediatr Perinat Epidemiol 2007 Jan;2I(I):65-75.

2. Wullink M, van Schrojenstein Lantman-de Valk HM, Dinant GJ, Metsemakers JF. Prevalence of people with intellectual disability in the Netherlands. J Intellect Disabil Res 2007;5 I (Pt 7):5 I I-9.

3. White P, Chant D, Edwards N, Townsend C, Waghorn G. Prevalence of intellectual disability and comorbid mental illness in an Australian community sample. Aust N Z J Psychiatry 2005;39(5):395-400.

4. McConkey R, Mulvany F, Barron S. Adult persons with intellectual disabilities on the island of Ireland. J Intellect Disabil Res 2006;50(Pt 3):227-36.

5. Instituto Nacional de Desarrollo Social. Disponible en: http://www. indesol.gob.mx

6. Costello H, Bouras N. Assessment of mental health problems in people with intellectual disabilities. Isr J Psychiatry Relat Sci 2006;43(4):24I-5I.

7. Ouellette-Kuntz H, Garcin N, Lewis ME, Minnes P, Martin C, Holden JJ. Addressing health disparities through promoting equity for individuals with intellectual disability. Can J Public Health 2005;96 Suppl 2:S8-22.

8. Eastgate G, Lennox NG. Primary health care for adults with intellectual disability. Aust Fam Physician 2003;32(5):330-3.

9. Lotan M, Henderson CM, Merrick J. Physical activity for adolescents with intellectual disability. Minerva Pediatr 2006;58(3):219-26.

10. Temple VA, Walkley JW. Perspectives of constraining and enabling factors for health-promoting physical activity by adults with intellectual disability. J Intellect Dev Disabil 2007;32(I):28-38.

II. Temple VA, Frey GC, Stanish HI. Physical activity of adults with mental retardation: review and research needs. Am J Health Promot 2006;2I(I):2-12.

12. Caballo C, Crespo M, Jenaro C, Verdugo MA, Martinez JL. Factor structure of the Schalock and Keith Quality of Life Questionnaire (QOLQ): validation on Mexican and Spanish samples. J Intellect Disabil Res 2005;49(Pt 10):773-6.

13. Verdugo MA, Cordoba L, Gomez J. Spanish adaptation and validation of the Family Quality of Life Survey. J Intellect Disabil Res 2005;49(Pt 10):794-8

14. McConkey R, Abbott S, Walsh PN, Linehan C, Emerson E. Variations in the social inclusion of people with intellectual disabilities in supported living schemes and residential settings. J Intellect Disabil Res 2007 Mar;5I (Pt 3):207-I7.

15. Maulik PK, Darmstadt GL. Childhood disability in low- and middleincome countries: overview of screening, prevention, services, legislation, and epidemiology. Pediatrics 2007 Jul; I 20 Suppl I:SI-55.

16. Verdugo MA. Research on mental retardation: an agenda for the future. Psychol Rep 2000;86(3 Pt 2): I 89-99.

17. Read S, Elliott D. Exploring a continuum of support for bereaved people with intellectual disabilities: a strategic approach. J Intellect Disabil 2007 Jun; I (2): 167-8I.

18. Verdugo MA, Schalock RL, Keith KD, Stancliffe RJ. Quality of life and its measurement: important principles and guidelines. J Intellect Disabil Res 2005;49(Pt I0):707-I7.

\footnotetext{
* Director del Centro de Investigación en Salud Poblacional, Instituto Nacional de Salud Pública.

‡ Capacitación y Desarrollo Integral, AC, Universidad Nacional Autónoma de México.
} 